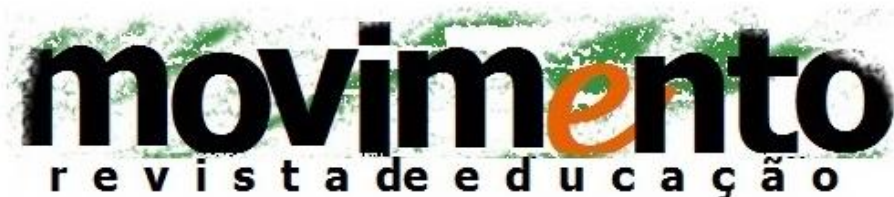

faculdade de educação - programa de pós-graduação em educação

universidade federal fluminense issn 2359-3296

ano 3 número 5 - 2016

\section{MULHERES NO PROEJA: desafios na conciliação entre família, trabalho e estudo}

\author{
Jessika Matos Paes de Barros ${ }^{1}$ \\ Regina Magna Bonifácio de Araújo²
}

\section{RESUMO}

O artigo apresenta resultados parciais de pesquisa concluída que buscou conhecer como se caracterizam as trajetórias escolares e profissionais de alunos diplomados pelo PROEJA. O referencial teórico conjuga os campos da educação, história da educação e sociologia. O caminho metodológico adotado foi da pesquisa qualitativa a partir dos estudos biográficos. Importante assinalar as questões relacionadas às responsabilidades assumidas pelas mulheres investigadas, diplomadas no PROEJA, que elaboram e concretizam suas estratégias de conciliação entre família, trabalho e escola.

Palavras-chave: PROEJA; Educação de Jovens e Adultos; Trajetórias Escolares e Profissionais.

\section{ABSTRACT}

The article presents partial results of research completed that aimed to know how to characterize the school and professional trajectories of graduate students at PROEJA. The theoretical framework combines the fields of education, history of education and sociology. The methodological approach adopted was the qualitative research from biographical studies. We consider it important to point out in this text, issues related to the multiple responsibilities taken daily of how the women investigated, registered in PROEJA, develop and accomplish their reconciliation strategies between family, work and school.

Keywords: PROEJA; Youth and Adult Education; Professionals and Scholarly Trajectories.

1 Mestre e Doutora em Educação pelo Instituto de Educação da Universidade de Lisboa, professora da SEDUC-Secretaria de Estado de Educação no Estado do Mato Grosso jessikamatos@yahoo.com.br

2 Mestre e Doutora em Educação, Pós-doutorado pela Universidade de Lisboa. Professora Adjunto III da UFOP, docente e pesquisadora do PPGE-Mestrado em Educação da UFOP. regina.magna@hotmail.com 


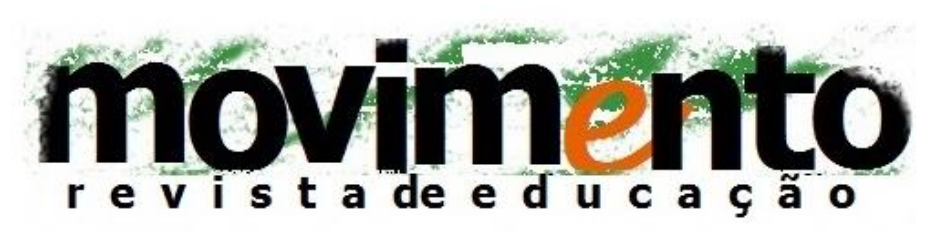

faculdade de educação - programa de pós-graduação em educação

universidade federal fluminense issn 2359-3296

ano 3 número 5 - 2016

\section{Introdução}

Em pleno século XXI, o trabalho e a família continuam sendo os eixos organizadores da vida de homens e mulheres não sendo estes diferentes e nem indissociáveis, pelo contrário, complementares. Segundo Goldani (2002, p. 30): "O mito de que o trabalho e a família eram dois mundos separados, acabou. E o reconhecimento da importância das relações entre estes, passou a guiar não só as discussões acadêmicas como também as políticas sociais".

Neste cenário observa-se ainda a alteração quanto à composição do núcleo familiar tradicional, que antes se considerava apenas os homens adultos como provedor da família, mas nas últimas décadas, esse papel perdeu força diante da posição assumida progressivamente pela mulher no mundo do trabalho. Em que pese o avanço em direção do fim do patriarcado na esfera pública o mesmo fenômeno não se repete quando se trata da divisão do trabalho doméstico.

Diante das responsabilidades múltiplas que cada indivíduo deve assumir dentro do contexto da sua família e junto à sociedade, cabe a indagação: como os atores sociais, diplomados no PROEJA, enfrentam as tensões e desafios da conciliação entre família, trabalho e escola? Que estratégias elaboram nessa conciliação? Estas estratégias se diferenciam entre homens e mulheres? Também são diferentes aquelas usadas pelos que são solteiros ou casados sem filhos, e os que são solteiros, casados/separados/viúvos, mas com filhos? A pesquisa que deu origem a este artigo foi realizada em 2014 na cidade de Cuiabá, com alunos formados pelo PROEJA ${ }^{3}$. Para responder às questões

\footnotetext{
3 Programa Nacional de Integração da Educação Profissional com a Educação Básica na Modalidade de Educação de Jovens e Adultos.
} 


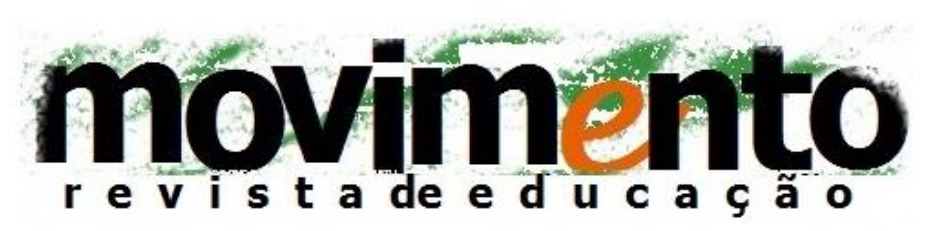

faculdade de educação - programa de pós-graduação em educação

universidade federal fluminense issn 2359-3296

ano 3 número 5 - 2016

norteadoras da investigação, optou-se por realizar uma investigação sob o paradigma de pesquisa qualitativa a partir dos estudos biográficos enquanto método e estratégia de pesquisa de campo. Quanto ao fundamento teóricofilosófico, destaca-se que a inspiração deste trabalho segue as linhas da fenomenologia, do interacionismo simbólico, e da etnometodologia (CHIZZOTTI, 2000), que apesar de serem correntes filosóficas diversas, podem ser utilizadas em conjunto por apresentarem pontos de convergências tais como a oposição ao positivismo e por priorizarem o valor do vivido e da experiência.

Para atingir os objetivos propostos, delimitaram-se os critérios de seleção dos sujeitos, bem como o espaço geográfico e temporal da investigação. Enquanto critérios de seleção, os sujeitos deveriam ter mais de 18 anos, serem diplomados pelo PROEJA, nível médio, oferecido em uma Rede de Ensino Estadual do Estado de Mato Grosso, e terem concluído o curso há mais de dois anos, ou seja, terem frequentado a oferta formativa entre os anos 2009 a 2011. O período de dois anos após a diplomação foi estabelecido considerando um tempo mínimo necessário para uma melhor análise da situação do percurso escolar e profissional dos sujeitos antes e após a diplomação. Essa delimitação temporal também coincide com as datas da implantação do PROEJA no Estado do Mato Grosso, na Rede Estadual no interior dos CEJA's - Centro de Educação de Jovens e Adultos, criados com o objetivo de atender exclusivamente ao público da EJA. Quanto à decisão da pesquisa centrar-se em alunos diplomados em PROEJA da Rede Estadual, foi relevante pois há muitas instituições autorizadas a ofertar tal modalidade, como Instituições Federais de Educação (IF's); Associações Civis ou ONG; a Rede do "Sistema S" de ensino, e instituições privadas. Mas é na Rede Estadual que existe a maior concentração de procura pelo curso, o maior índice de abandono e menor número de pesquisas. 


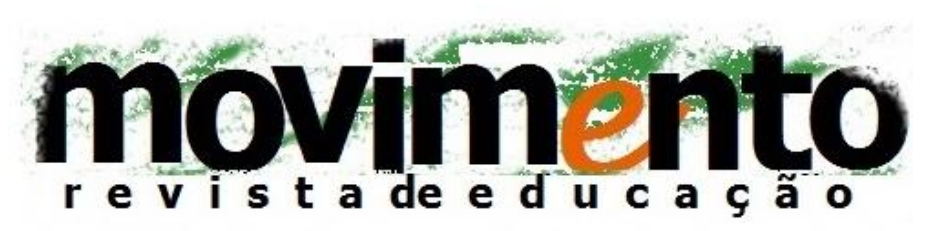

faculdade de educação - programa de pós-graduação em educação

universidade federal fluminense issn 2359-3296

ano 3 número 5 - 2016

Com essas considerações feitas, as entrevistas biográficas foram realizadas com alunos e alunas diplomados pelo PROEJA - Técnico Administrativo, oriundos dos CEJA's Licínio Monteiro e José de Mesquita da Rede Estadual do Mato Grosso. Segundo dados oficiais das escolas pesquisadas, no CEJA Licínio Monteiro, estiveram matriculados no ano 2009 o número de 114 alunos no $1^{\circ}$ ano, e destes saíram diplomados 33 alunos. E no CEJA José de Mesquita, em 2009, o número de alunos inscritos no $1^{\circ}$ ano foi de 150 , e ao fim do curso, em 2011, se diplomaram 21 alunos. Portanto, nos dois Centros somam-se o total de 269 matrículas no curso Técnico em Administração em 2009, no entanto, somente 54 alunos se diplomaram, o que indica um alto índice de abandono escolar nos dois cursos, numa proporção de $80 \%$. Dos 54 diplomados, 38 foram entrevistados.

Os contextos sociais do grupo entrevistado e suas trajetórias profissionais apresentam em termos de perfil a predominância do gênero feminino; casados com dois filhos em média e aproximadamente 40 anos de idade. Quanto ao grupo doméstico, este se caracteriza com baixa ou nenhuma habilitação escolar, cujo exercício profissional está relacionado ao trabalho para outrem ou por conta própria em áreas rurais, dedicados à lavoura e criação de animais, com baixa perspectiva remuneratória. Quanto às trajetórias escolares dos participantes, estas são marcadas pela inserção inicial em escolas predominantemente rurais, de pouca qualidade e ausência de oportunidades de continuidade escolar, cujas rupturas são consequências de fatores externos e internos, relacionadas tanto ao perfil quanto ao contexto social e de funcionamento do sistema escolar, chegando atingir a média de 20 anos fora da escola, sendo na maior parte dos casos, o trabalho a maior barreira para a concretização da escolarização. $O$ retorno escolar se apresenta, em razão da distorção idade-série, realizado através de modalidades supletivas como a EJA - Educação de Jovens e Adultos, 


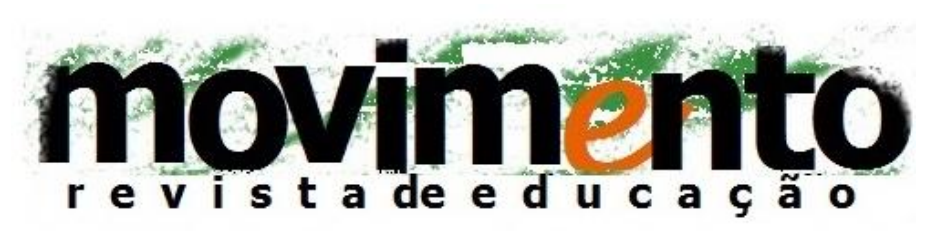

faculdade de educação - programa de pós-graduação em educação

universidade federal fluminense issn 2359-3296

ano 3 número 5 - 2016

para a conclusão do ensino obrigatório. Com relação a trajetória laboral, o grupo se caracteriza pela inserção precoce no mercado de trabalho e a manutenção de atividades de pouca exigência de qualificação ao longo da transição da juventude para fase adulta, bem como atividades temporárias e inseridas na economia informal. Dentre as motivações para realizar o PROEJA, destaca-se o interesse de obter o diploma e uma profissão como ferramentas de empregabilidade e mobilidade social.

\section{As desigualdades de gênero}

Debates e reflexões sobre a origem das desigualdades de gênero não são recentes e diversos organismos internacionais fornecem contribuições para a compreensão, o combate e a prevenção das desigualdades tais como a ONU Organização das Nações Unidas, o Fundo para as Populações das Nações Unidas ou a OIT- Organização Internacional do Trabalho.

Nos anos 1980, a categoria gênero surge de forma ampla no discurso políticoinstitucional, e a partir desse marco, não obstante as consideráveis alterações ocorridas no sentido de avanços no tratamento dos direitos igualitários nas esferas político-jurídico-legal, tanto na Europa quanto no Brasil, ainda há um longo caminho a percorrer na busca da plena garantia da igualdade de gênero para além da retórica e do campo legal.

$\mathrm{Na}$ vertente sociológica, essa questão tem interpretações diferentes. Na ótica estrutural-funcionalista destaca-se o conceito elaborado segundo a visão de Parsons (1956), na qual a mulher seria socializada para "[...] desempenhar um 


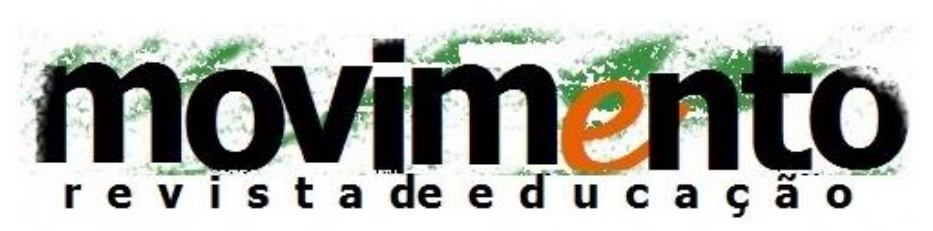

faculdade de educação - programa de pós-graduação em educação

universidade federal fluminense issn 2359-3296

ano 3 número 5 - 2016

papel de líder expressivo na família, função que garantiria o bem-estar dessa unidade social; já o homem seria socializado de forma a exercer uma função de sustento e garante da satisfação das necessidades da família" (AMÂNCIO e OLIVEIRA, 2002, p. 46).

Nesse cenário, as mulheres representam-se e são representadas socialmente em termos de grupo dominado, com uma esfera de ação restrita ao universo da família, e em contrapartida, ao homem é possível haver uma multiplicidade de papeis. Portanto, estes papeis são assimétricos em termos de conteúdo e forma, pois "A definição de pessoa adulta, subjacente ao estereótipo feminino, encontra-se assim limitada às funções afetivas e de objeto de desejo, às quais se associa a ausência de qualidades para o trabalho e para a autonomia" (AMÂNCIO, 1994, p. 64).

Com base nessa concepção, o que se espera encontrar nas atividades da mulher que trabalha, para além da esfera domiciliar, é a realização de tarefas ligadas a esse mesmo olhar, como uma extensão das atividades domésticas, como o ensinar e cuidar, pois estes são os comportamentos a elas associados para o mundo do trabalho. Nesse contexto cabe lembrar a obra de Bourdieu (2002), na qual ressalta que o masculino exerce uma dominância simbólica sobre 0 feminino, que é criada na lógica do discurso da naturalização do social, e é essa dominância simbólica que divide o mundo em masculino e feminino. Para o autor, este cenário vem sofrendo relativa transformação, e os fatores que contribuíram para isso são essencialmente o acesso da mulher à esfera pública (ensino superior, secundário e trabalho remunerado) e o distanciamento (relativo) das tarefas domésticas e das funções reprodutivas. A condição invisível da mulher, cerceada pela esfera doméstica de ação e atuação, a mantém vítima de um papel subalterno na sociedade. É preciso notar que, segundo destaca Louro 


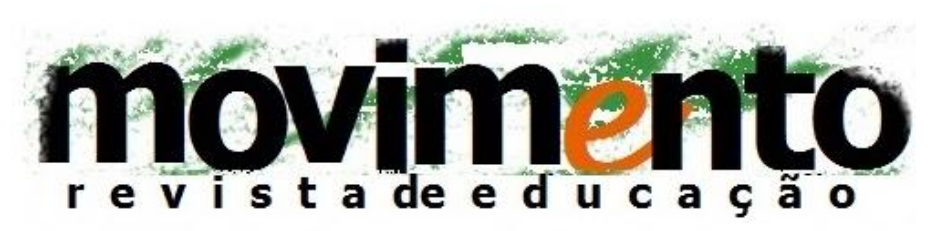

faculdade de educação - programa de pós-graduação em educação

universidade federal fluminense issn 2359-3296

ano 3 número 5 - 2016

(1997, p. 17), "[...] essa invisibilidade, produzida a partir de múltiplos discursos que caracterizaram a esfera do privado, o mundo doméstico, como o 'verdadeiro' universo da mulher, já vinha sendo gradativamente rompida, por algumas mulheres". Nessa condição as mulheres continuam sobrecarregadas, "[...] quer com o trabalho remunerado, quer com o trabalho doméstico não remunerado 0 que acabou por gerar o surgimento das mulheres trabalhadoras com a 'identidade de supermulher"' (CASTRO, 1997, apud AMÂNCIO E OLIVEIRA, 2002, p. 51).

São estas características, bem como a ocultação do rotineiro trabalho doméstico, que passa a ser alvo de interesse. Como realizam suas tarefas nos diferentes espaços? Que estratégias criam para apaziguar as tensões e conciliar o tempo? Em que essas estratégias se diferenciam daquelas realizadas pelos homens?

As formas de conciliação da vida profissional com a vida familiar é um tema que emerge no fim da década de 1960 em decorrência de vários elementos conjugados, tais como o aumento da participação das mulheres no mercado de trabalho, a rejeição a modelos de família assente no provedor masculino, a flexibilidade e intensificação dos tempos de trabalho, a persistente desigualdade de gênero face ao emprego e ao trabalho doméstico da mulher.

Um dos estudos pioneiros nessa área, e que analisaram as questões da relação entre a família e o trabalho, são os desenvolvidos por Rapoport e Rapoport (1965). A explosão e multiplicidade de estudos a partir de então é resultado em parte de um vigoroso debate político e científico e, ainda, em decorrência da construção de sexo e de gênero "[...] como categorias e como realidades históricas emergentes, no qual os textos feministas tornaram-se proeminentes 


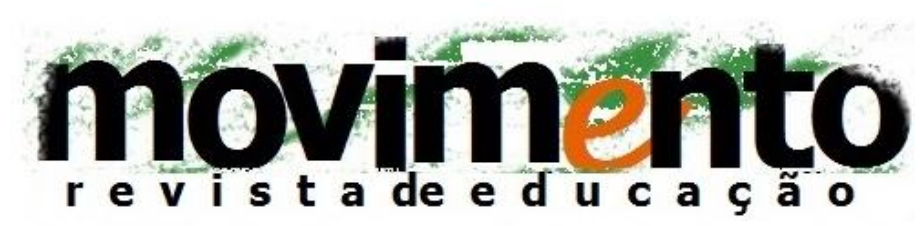

faculdade de educação - programa de pós-graduação em educação

universidade federal fluminense

issn 2359-3296

ano 3 número 5 - 2016

em meados dos anos setenta, principalmente na crítica ao determinismo biológico" (HARAWAY, 2004, p. 222).

Outra questão que os estudos mais recentes questionam é o fato de que, até os idos de 1970, o tema família e trabalho eram tratados como mundos diferentes e separados, e agora os conceitos tendem mais para o caráter complementar entre essas duas realidades.

As primeiras pesquisas acerca da relação entre trabalho e vida familiar, centraram-se nas características do trabalho, com os níveis de rotina e o grau de autonomia na execução das tarefas, ou a sua complexidade procurando averiguar o modo como estas características condicionam a vida familiar, e os estudos posteriores concentraram-se de forma muito marcadas nas questões do stress profissional e estiveram ligadas à afirmação da perspectiva do conflito de papéis na análise ao sistema trabalho/família (NÚNCIO, 2008, p.17).

A partir de 1990, as investigações entre a vida familiar e profissional se voltam para a dimensão organizativa da conciliação cotidiana dos tempos para a família e para o trabalho, para estratégias familiares e diferenças de gênero. Núncio (2008, p. 23) assinala ainda que

[...] em termos das ciências sociais, o interesse pela origem das novas perspectivas de gênero, radica na evolução das sociedades de Pós-Segunda Guerra Mundial e nas amplas transformações na organização econômica, política e social vividas pela generalidade dos países ocidentais, e se afirma muito mais quando essa realidade se confronta com o fato da manutenção de ideologias segregacionista enraizada nas próprias diferenças biológicas entre os sexos. 


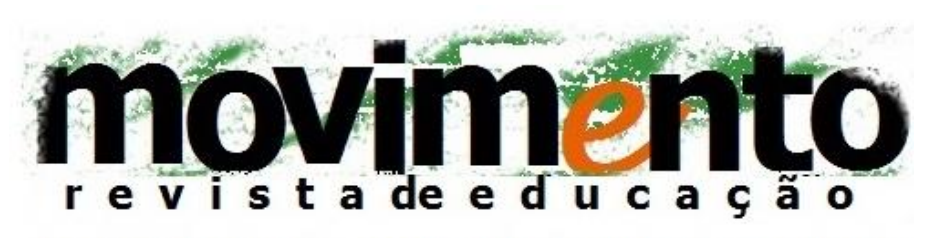

faculdade de educação - programa de pós-graduação em educação

universidade federal fluminense

issn 2359-3296

ano 3 número 5 - 2016

Atualmente a importância da defesa da igualdade de gênero, continua a ser reconhecida internacional e nacionalmente como uma prioridade para alcançar "[...] a igualdade de gênero, o aumento da participação das mulheres no mercado de trabalho e a promoção da partilha paritária das responsabilidades e tarefas de cuidar entre homens e mulheres" (DOMINGOS, 2012, p. 3). Entretanto, em que pese observarem-se alguns avanços em termos de equiparação entre os direitos e deveres de homens e mulheres no campo da saúde e educação, contudo no âmbito econômico e profissional, apresenta-se um alto nível de disparidade.

Família, trabalho e escola: estratégias de conciliação dos diplomados no PROEJA.

Em relação ao grupo de diplomados no PROEJA, e aos temas família e trabalho, a família aparece como eixo norteador dos projetos de vida e esse fato possivelmente se explica em razão de ser este um elemento socializador por excelência, por ser o primeiro grupo social ao qual pertence uma pessoa e no qual se espelhará para tomar futuras decisões. No grupo investigado predomina a condição civil de casado com uma média de dois filhos. Sendo que, o casamento e os primeiros filhos, para a maioria dos sujeitos entrevistados, ocorreu antes dos 20 anos. Um cenário que se apresenta em boa parte dos relatos como justificativa para a descontinuidade escolar e profissional (principalmente no caso das mulheres).

No entanto, o trabalho se destaca como prioridade desde a adolescência. Todos relataram experiência laboral antes dos 18 anos seja na condição remunerado 


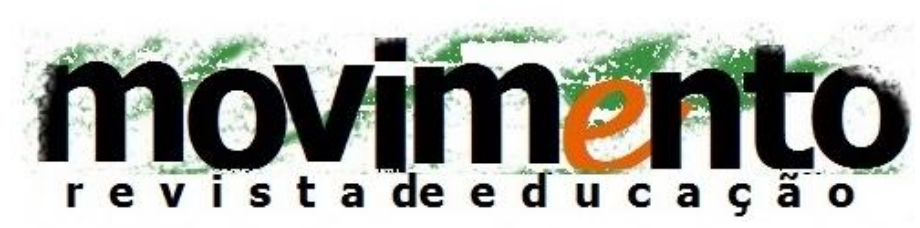

faculdade de educação - programa de pós-graduação em educação

universidade federal fluminense

issn 2359-3296

ano 3 número 5 - 2016

ou não. É a partir de uma experiência laboral precoce que, ao longo da vida, surge também a necessidade de se criarem estratégias de divisão do tempo entre a família (eixo norteador da vida); o trabalho (fonte de subsistência) e os estudos (oportunidade de melhoria de vida).

Para conhecer as diferentes estratégias de conciliação desse grupo foi importante separá-las por sexo e também entre aqueles sujeitos que se apresentam sem filhos, daqueles que se apresentam com filhos. Primeiro vamos analisar as questões da conciliação e estratégias praticadas pelos homens com e sem filhos e suas estratégias de conciliação entre o tempo a ser dedicado a família, aos estudos e ao trabalho:

\begin{abstract}
Mário: Foi muito difícil (trabalhar e estudar), porque eu tinha que sair correndo rapidamente, tomar banho rapidamente. Tem dia que ia até meio fedendo para a escola. Mas tem que, não tinha aquele tempo né. Ai você chegava lá e vinha, várias vezes pensava em desistir, mas graças a Deus, deu certo e fechei os três anos. Foi muito difícil porque você sai pra rua, você fica o dia inteiro na rua. Por exemplo: eu dirigia uma Kombi, tomava conta de uma freguesia então eu tinha uma freguesia de 430 clientes. Várias vezes pensei desistir.
\end{abstract}

Dinis: Trabalhava de office boy na factoring, lá era meio período. Era das uma até as seis. De segunda a quinta ai sexta-feira saía às 5 horas. Depois de um tempinho comecei a trabalhar tipo integral. Nesse tempo morava com uma tia ou ficava na casa da minha vó porque era mais perto da escola.

Walter: Entrava na Sadia [indústria de alimentos] às 07h00 e largava as 17 h00 e ia para escola. la de ônibus. Nessa época minha mãe já tinha morrido, e estava só meu pai. No outro emprego, na Coca-Cola, pegava as $08 \mathrm{~h} 00$ parava as $11 \mathrm{ho0}$, voltava 12h00, e saía as 17 h00 e ia correndo para o colégio.

Estes entrevistados apresentam uma condição semelhante entre si, que é o fato de não terem filhos, mas também apresentam um ponto diferenciador. Dinis e Walter são solteiros e Mário é casado. Este último, mesmo casado não menciona 


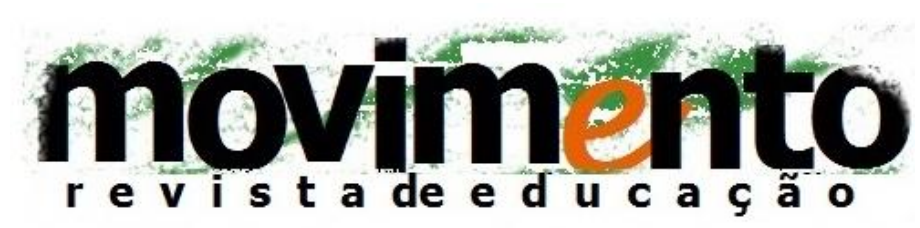

faculdade de educação - programa de pós-graduação em educação

universidade federal fluminense

issn 2359-3296

ano 3 número 5 - 2016

haver conflito entre o tempo a ser dedicado à família, ao trabalho e à escola, mas mencionam, assim como os demais colegas na mesma condição (sem filhos), que dentre os desafios de conciliação está a superação do cansaço, a falta de tempo para comer ou tomar banho ou se dedicar às tarefas escolares.

Enquanto estratégias de conciliação mencionam a mútua colaboração entre os colegas nas tarefas escolares; acordo de redução de horas de descanso no trabalho para cumprir o horário da escola ou redução da jornada de trabalho para meio período. No grupo entrevistado, não há casos de mulheres solteiras ou sem filhos.

Para dar conta do desafio de organizar os tempos dedicados ao trabalho e aos estudos quando se é solteiro ou casado, mas com filhos, é diferente daqueles que não os tem. Para os diplomados homens na condição de casados ou separados, com filhos (pequenos, adolescentes ou adultos), assim relatam as tensões na conciliação e as estratégias utilizadas:

Simão: Matriculei-me para começar a $5^{\underline{a}}$ série depois de muito tempo se estudar. Mas parei por causa do trabalho. Trabalhava de motorista de entrega da CocaCola, e não tinha hora para voltar para casa. Já era casado e tinha três filhos, na época eles eram pequenos, eu só os via dormindo, eu chegava eles estavam dormindo. Eu deixava dinheiro para eles fazerem lanche no colégio. Tentei voltar a estudar, mas houve um período, minha mulher (...) teve um período que me deixou com as crianças. E de novo não podia estudar. Aí parei de estudar de vez e fui só trabalhar para criar meus filhos. Nessa altura eu já tinha 34 anos. Só depois, com os filhos adultos, voltei a estudar e terminei o Proeja.

Mauro: Eu tive que trabalhar desde cedo. Eu carpia, roçava o dia todo e vivia na casa de um irmão ou um tio. Arranjei um trabalho em um viveiro, tipo horto, e morava lá aos dezesseis anos. Depois casei e fui trabalhar de pedreiro, tinha assim aquele sonho de estudar. Mas muitas vezes minha esposa dizia tem que decidir entre 'colégio ou eu'. Ela não queria que eu estudasse. Nós tínhamos três filhos pequenos na época. Dois delas e o nosso. Eu falava: 'os dois'. Estudar era 


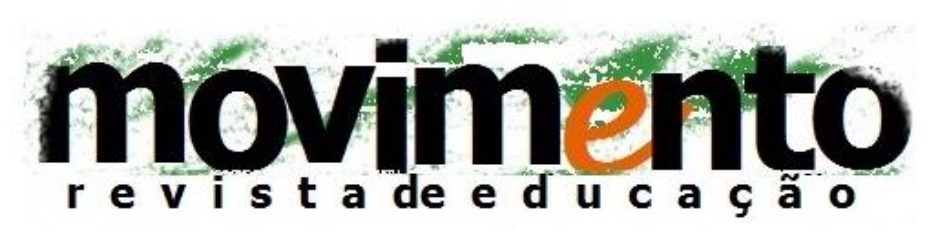

faculdade de educação - programa de pós-graduação em educação

universidade federal fluminense issn 2359-3296

ano 3 número 5 - 2016

meu sonho. Mas só depois que eles cresceram que voltei para escola para terminar o ensino fundamental.

Dentre os desafios de conciliação narrados acima se destacam a falta de tempo para se dedicar a leitura ou tarefas escolares, bem como falta de tempo para um descanso intervalar entre o trabalho e a escola (para um banho ou alimentação) e, principalmente, como o trabalho dificulta conciliar as responsabilidades. Portanto, se comparamos os desafios mencionados pelos homens solteiros e casados sem filhos com aqueles solteiros ou casados com filhos, os desafios e algumas das estratégias de conciliar trabalho e estudos são semelhantes, principalmente aquelas relacionadas à própria escolaridade quanto ao horário de frequência escolar e à divisão das tarefas escolares com colegas. Mas em termos de conciliação entre trabalho, família e estudos incluindo os cuidados com filhos, as estratégias se configuram de forma diversas. Para aqueles com filhos pequenos, alguns mencionam a ajuda das esposas e família, e outros apontam terem esperado um momento oportuno para o retorno à escola, o que se deu com o crescimento dos filhos.

Vejamos a seguir como os relatos das mulheres diplomadas em PROEJA mencionam essas situações de conflitos e como se organizam com intuito de superá-los.

Em todos os relatos, para as mulheres entrevistadas, a família se apresentou como prioridade, principalmente em se tratando daquelas com filhos pequenos, em detrimento do trabalho e principalmente dos estudos. O fato de terem (na maioria) assumido o papel de esposa e de mãe muito jovem (com uma média de 18 anos), muitas se viram impedidas por várias razões, de prosseguirem os estudos e de investirem em uma carreira profissional. Dentre essas razões 


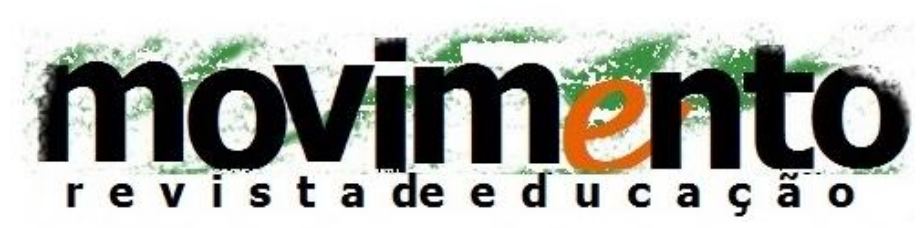

faculdade de educação - programa de pós-graduação em educação

universidade federal fluminense

issn 2359-3296

ano 3 número 5 - 2016

impeditivas estão: crianças pequenas e falta de apoio ou suporte da parte do companheiro, ausência de políticas públicas que garantam a oferta de vagas em creches e a baixa ou nenhuma remuneração que pudessem subsidiar a terceiros tais cuidados.

Diferentemente do que foi relatado pelos homens, todas as entrevistadas mencionaram os conflitos existentes entre a necessidade de cuidados com a casa, com filhos, os estudos, e ainda o trabalho. Sobre o tema do trabalho, não se pode deixar de mencionar a discussão atual em torno da questão do trabalho remunerado e o não remunerado (doméstico familiar) e, inserido nesse último, a discussão sobre a (não) divisão das tarefas domésticas. Assim considerando todos estes pontos acima mencionados, algumas mulheres relatam que:

Elisa: Antes de solteira, trabalhava das 05 h30 da manhã e voltava 24 h00 (meia noite) depois casei e por causa dos filhos, mudei para outro trabalho num mercado. Ganhava menos e trabalhava mais pesado, mas era mais perto. Como meu marido viajava a trabalho, deixei esse emprego e abri um salão de beleza em casa, assim cuidava das crianças e trabalhava. Assim podia fazer os dois. Fui criando meus filhos e com salão em casa, e juntando dinheirinho para educar eles, e ajudando meu marido. Quando eles eram grandes pude voltar a estudar.

Marcela: Depois que meu marido me abandonou com os três filhos pequenos eu fui arranjar outros trabalhos além do que já fazia, já era merendeira numa escola para poder manter a casa. As crianças, só Deus para ajudar, às vezes numa creche, noutras na casa de alguém ou com babá. Tempos difíceis. Fiquei muitos anos sem estudar, só depois que eles cresceram pude voltar.

Georgia: Eu trabalhava de manhã e à tarde, e com esse dinheiro que era de meio período, eu pagava a menina para ficar com meu filho. Que ai de tarde eu pagava uma e noite pagava outra. Assim dava para eu estudar. Meu marido não tinha tempo para cuidar das crianças. Se tivesse creches seria mais fácil. 


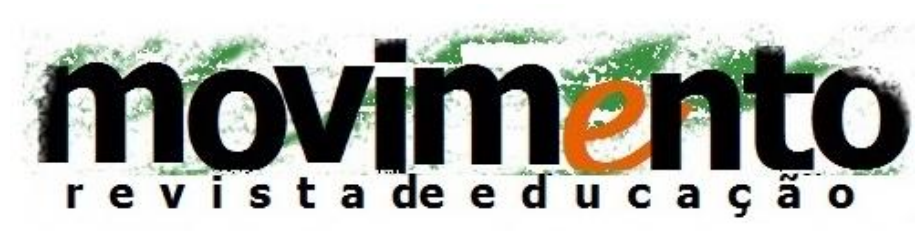

faculdade de educação - programa de pós-graduação em educação

universidade federal fluminense

issn 2359-3296

ano 3 número 5 - 2016

Em relação aos conflitos, as entrevistadas destacam a dificuldade em trabalhar e cuidar das crianças sem poder contar com a ajuda do parceiro; a necessidade de pagar a terceiros pelos cuidados com as crianças de forma a poder estudar e trabalhar e, ainda, a ausência de creches. Em termos de estratégias de conciliação, em comum apresentam o fato de colocarem como prioridade a família em detrimento do trabalho e da própria escolarização. Para além da rotina que não é fácil conciliar, alguns relatos mencionam a não colaboração do marido e, ainda, a necessidade de superar a declarada oposição deste em relação aos estudos e ao trabalho fora de casa. Uma situação é não ajudar, outra diferente é não permitir que estude ou trabalhe, ou ainda dificultar esta conciliação. Alguns relatos demonstram essa situação, vivenciada pelas mulheres desse grupo de entrevistadas.

Irene: Eu sempre enfrentei dificuldade em estudar. Meu marido bebia muito, ficava doente, brigava comigo, não deixava eu estudar. Eu passava uma dificuldade muito grande. Já os filhos adultos, recente, no PROEJA, foi uma das épocas de estudo mais difícil, foi esse aí. Por isso tem hora, que eu olho meus cadernos, que tem tanta coisa boa, que a gente vai passando vendo as dificuldades, as doenças. Mas aprendi muita coisa, só sinto ter tido tantos problemas na família para não aprender mais. Já na minha idade, e querer estudar, e cheia de problemas na família. E nessa época, meu marido, falei para você, em 2009 ele faleceu. Assim pude terminar os estudos.

Adriele: Depois na $8^{\underline{a}}$ engravidei e casei. Tive dois filhos, nessa época não estudava nem trabalhava, só cuidava das crianças. Meu marido não apoiava, tinha ciúmes. Com as crianças já grandes, separamos. Eu voltei a trabalhar e estudar e agora tenho um negócio próprio, meu salão de beleza, sou autônoma.

Nestes casos, a viuvez e a separação foram elementos que contribuíram enquanto oportunidades de retorno à escola e ao mundo do trabalho fora de casa. A opção de levar os filhos para a escola foi mencionada pelas colegas 


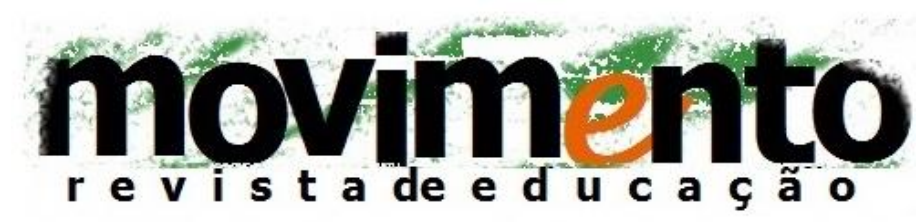

faculdade de educação - programa de pós-graduação em educação

universidade federal fluminense issn 2359-3296

ano 3 número 5 - 2016

Selma e Jocelina como estratégia de conciliação para prosseguir com os estudos:

Selma: Eu tinha medo de deixar a menina em casa, então levava comigo para escola. Ela estudava de manhã e noite ia para o colégio comigo e o pai. É que $o$ bairro é muito perigoso.

Jocelina: Com 27 anos quando 'tava' estudando, engravidei e tive essa menina [segunda filha] mas estudei normal, porque essa, parava com todo mundo e dava para levar para o colégio ou deixar em casa com alguém da família.

Entre as estratégias mencionadas, para além de levar as crianças para o colégio e contar com ajuda de familiares, algumas das participantes relatam que para poderem estudar elas precisavam manter a rotina da casa funcionando regularmente, como limpeza e refeições, para não ouvirem reclamação do marido, evitando com isto, maiores conflitos.

Lucilene: Eu moro longe do colégio, à noite, ia e voltava à pé. Meu marido não gostava que eu estudasse, então ele tem vez ele fica com 'bicão', porque ele chegava à casa não tinha comida, aquilo outro... Mas eu não fazia caso. Dificuldade de ter um marido assim, arcaico, sempre assim, se eu tenho, por exemplo: eu tinha uma menina pequena com quem eu ia deixar? Se ele falou que ele não ia cuidar. Neste período não podia estudar. Mas depois elas cresceram. As pessoas nunca acreditam na gente. Dizem: 'Que você quer estudar? Já está velha'. As pessoas que são atrasadas, que deixaram de estudar acham que não tem o direito de voltar a estudar. Eu senti muita discriminação na rua, na sociedade, de conhecidos, vizinhos, parente mesmo. Chegavam para mim: 'O que você está querendo estudar? Eu passava o dia inteiro em casa então eu fazia o máximo para conciliar os estudos, deixar tudo pronto, por exemplo: às 18 h00 tinha que estar tudo pronto: jantar, as crianças pequenas tomado banho, as outras maiores chegavam, e então eu saía de casa 18 h00 para chegar 18h40, a aula começava $18 h 40$. 


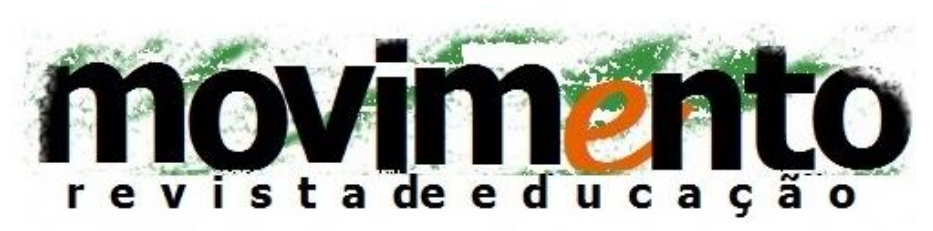

faculdade de educação - programa de pós-graduação em educação

universidade federal fluminense

issn 2359-3296

ano 3 número 5 - 2016

Dentre as estratégias utilizadas por estas entrevistadas para estudar, elas relatam, na sua maioria, que deixavam as tarefas do lar devidamente feitas com antecedência e contavam com a ajuda de filhos maiores para cuidar dos menores, de forma a poder frequentar escola no período noturno sem reclamações do marido. Estes relatos retratam a condição de fragilidade dessas mulheres perante a posição de dominação exercida pelos maridos, posto que, maioritariamente, não ajudam com os cuidados da casa ou dos filhos.

Várias autoras deram um contributo decisivo para a contestação destas concepções e suas implicações na desigualdade existente entre homens e mulheres, na esfera familiar e profissional, a exemplo de Acker (apud DOMINGOS, 2012, p. 77).

Um dos pressupostos que mais perpetua as assimetrias de poder entre os sexos é a noção do/a 'trabalhador ideal' que não tem responsabilidades familiares, apresenta uma disponibilidade a tempo inteiro para o trabalho, grande mobilidade geográfica, uma forte orientação para o trabalho, sem qualquer envolvimento com outras responsabilidades na vida, modelo que coincide precisamente com 0 modelo de masculinidade hegemónica e do papel de ganha-pão atribuído ao homem.

Enquanto para o homem lhe é reservado o destino de trabalhar, à mulher the fica reservado o de ser dona de casa. Segundo os relatos acima, algumas das entrevistadas somente conseguiram frequentar a escola após separarem-se de seus companheiros ou no caso de Irene, tornar-se viúva. Acontecimentos esses que marcam o limite entre o fim de um conflito familiar e a liberdade de trabalhar e estudar. Por outro lado, a condição machista na vertente da não permissão para estudar ou trabalhar, não é generalizada. Houve também relatos no sentido de que o parceiro ou parceira colaborou e colabora para a realização da 


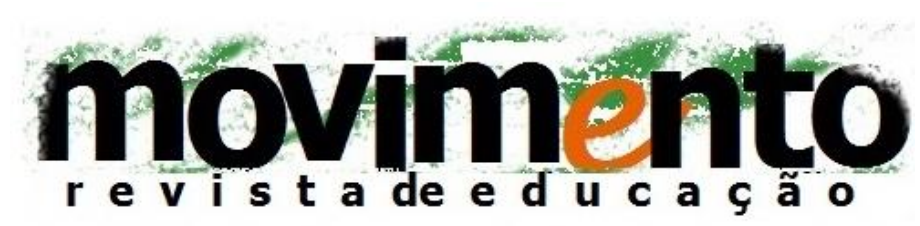

faculdade de educação - programa de pós-graduação em educação

universidade federal fluminense

issn 2359-3296

ano 3 número 5 - 2016

conciliação dos estudos com o trabalho, embora em número reduzido. Vejamos como narram as participantes a esse respeito:

Elisa: Meu marido trabalhava de noite, e durante o dia ele cuidava da casa e ajudava. À noite 'nós ia' para escola e fizemos a $7^{a}$ e $8^{\underline{a}}$ supletivo juntos. Aí tinha esse curso do PROEJA, que era o ensino técnico com $2^{\circ}$ grau. Voltei a estudar, pegava o ônibus, meu marido incentivava, minha filha também.

Rosália: Foi mais fácil, porque as crianças já estavam um pouco maior, mas a família ajudou bastante. Meu marido ajudava. Na época do Proeja trabalhava numa empresa de segurança, foi difícil no serviço era 12×36. Dia sim e outro não. E quando eu saía do serviço eu ia direto para escola. As crianças ficavam com meu sogro.

As narrativas tendem a indicar, portanto, que embora alguns maridos participem das responsabilidades dentro do lar, estas se restringem a estar com os filhos em casa, não necessariamente na realização das tarefas domésticas. Quanto à condição da não colaboração com os trabalhos domésticos e na divisão das tarefas no dia a dia, alguns relatos registrados merecem destaque:

Maria: O primeiro ano (do ensino médio) quando comecei, só trabalhava até as 15h00, e fazia o serviço de casa, e cuidava da minha mãe que mora comigo e é velhinha. Depois voltei para horário integral, então quase desisti. Estava muito cansada. Eu ia de bicicleta para escola e era longe.

Juraci: Depois de voltar a estudar, fiz a $5^{a}$ e $6^{a}$, $7^{a}$ e $8^{a}$ série à tarde com meu filho mais velho, cuidava do 'dever de casa de manhã' e quando eu levava as crianças pra escola de bicicleta eu também ia pra escola. À noite depois da escola, limpava casa, cuidava das roupas e da comida. Durante o Proeja foi igual.

Amália: Quando se é solteira, você só estuda e trabalha, mas quando tem filhos, que é casada, tem que fazer o jantar e cuidar de filho. Depois que voltei estudar, de manhã trabalhava e a tarde estudava. Meu filho ficava com minha mãe e eu ia trabalhar. Deixei de estudar muitas vezes por isso. 


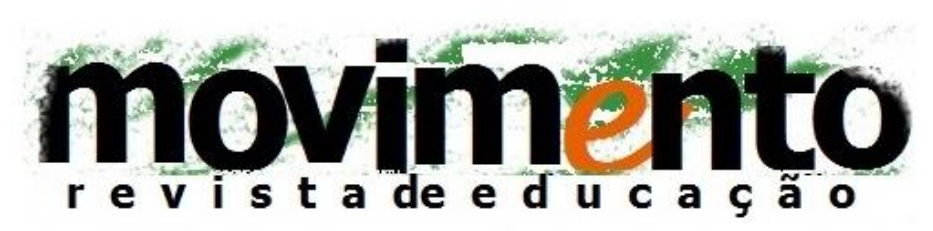

faculdade de educação - programa de pós-graduação em educação

universidade federal fluminense issn 2359-3296

ano 3 número 5 - 2016

Nestes relatos a condição do peso da responsabilidade nos cuidados da casa e com os filhos é clara, cabe à mulher. Não há menção da participação dos companheiros na divisão destas tarefas em relação aos cuidados dos filhos pequenos, nem na divisão das tarefas domésticas. Nesse caso nem as mulheres entrevistadas mencionam esse fato em relação aos seus maridos, nem os homens entrevistados mencionam realizar tais tarefas em relação às suas esposas.

Enquanto nos relatos dos homens estes mencionam o cansaço, a falta de tempo para comer e realizar tarefas escolares, ou dividir períodos em que a esposa ou ele estuda (em alguns casos) a título de desafios e estratégias, por outro lado, quando observamos os relatos das mulheres, estas não mencionam cansaço ou falta de tempo como empecilho para estudar. Preocupam em mencionar como desdobrar-se para dar conta do serviço da casa, seja antes de trabalhar ou depois, seja antes ou depois do horário da escola.

Enquanto estratégia de conciliação, como a prioridade é a família, muitas deixam de estudar ou trabalhar e outras contam com suporte de familiares, na maioria das vezes, a própria mãe ou, ainda, optam por levar a criança para escola e até mesmo pagar uma pessoa como babá. Com relação às estratégias utilizadas pelas mulheres (casadas e com filhos) para conciliar a divisão do tempo e poder estudar e trabalhar sobressai nos relatos o apoio de alguma instituição escolar (creches e escolas), levar as crianças para escola, pagamento a terceiros (babás) e principalmente o apoio da rede familiar. Assim nos registram algumas das entrevistadas acerca da rede de apoio como estratégias de conciliação: 


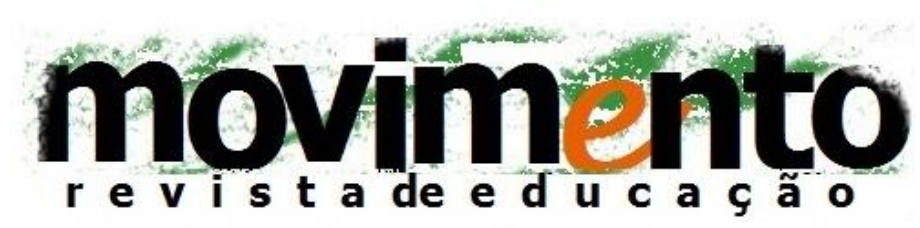

faculdade de educação - programa de pós-graduação em educação

universidade federal fluminense

issn 2359-3296

ano 3 número 5 - 2016

Gina: Não foi difícil estudar porque minha mãe cuidava do pequeno para mim. Ficavam com minha mãe de noite, depois que eu chegava eu pegava ela. Nessa época morava com minha mãe, não era casada. Depois casei e tive outro filho. Minha mãe continua a ajudar. Durante o Proeja, a dificuldade era quando não tinha ônibus escolar, e nem sempre, tinha dinheiro, e então a gente não ia. Quando meu marido chegava mais cedo do serviço, ele me levava, senão ia de escolar.

Laila: Não tive dificuldades. Nem um pouquinho. Não tinha barreira na época. Não tinha como eu falar não. Não tem quando você embala numa coisa? Minha mãe cuidava do bebê, e eu não trabalhava.

Ao falarem de seu dia a dia, as entrevistadas enfatizam a multiplicidade de tarefas, funções e responsabilidades que têm que enfrentar cotidianamente. Fica clara a longa e cansativa rotina de uma mulher que, além do trabalho remunerado, também cuida da casa, é esposa e mãe. Deste modo as mulheres inseridas no mercado de trabalho preocupam-se em demonstrar que são boas profissionais, mas também e, principalmente, que são mães extraordinárias e, ainda, gestoras da esfera doméstica (TORRES et al., 2005), numa reprodução dos papéis sexuais convencionais.

\section{Concluindo, mas não encerrando estas reflexões...}

A análise dos relatos aponta que, com relação à (não) divisão das tarefas domésticas e ao tempo dedicado a estas tarefas, quando observadas sob a ótica do gênero, há um consenso no fato de que as mulheres se dedicam muito mais que os homens e que o avanço na conscientização para divisão das tarefas domésticas, todavia é lento. A realidade que se enfrenta, da parte das mulheres, leva a confirmar a coexistência de valores tradicionais e de valores da modernidade. Por um lado, as mulheres interiorizaram de forma segura o seu 


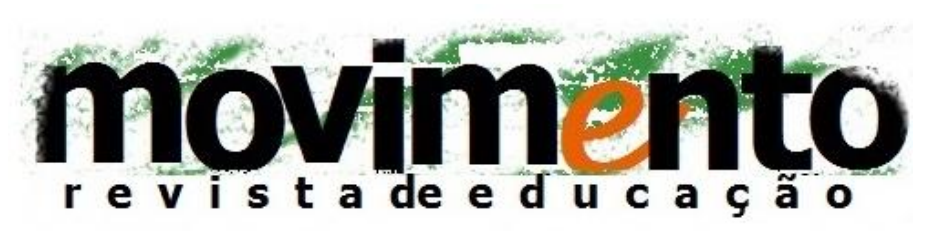

faculdade de educação - programa de pós-graduação em educação

universidade federal fluminense issn 2359-3296

ano 3 número 5 - 2016

direito ao emprego e ao estudo, mas por outro, mantém as responsabilidades familiares para si. Nesta direção, e alinhados ao pensamento de Núncio (2008) observa-se que as mudanças ao nível de papéis de gênero, se consubstanciaram fundamentalmente na crescente participação da mulher no trabalho, mas no ensino e na esfera privada da vida familiar, as tarefas domésticas continuam a ser maioritariamente da responsabilidade da mulher que deve concilia-las com as atividades laborais. Por outro lado, apesar de realizarem a dupla jornada, a maioria das mulheres não apresenta reclamação expressa da ausência da participação dos maridos nas tarefas domésticas.

Nos relatos do grupo de mulheres participantes dessa pesquisa, observou-se que embora não tenha havido expressamente nenhuma referência de repúdio ao fato do marido não ajudar nos deveres de casa, por outro lado, tampouco se observou nos relatos, menção a alguma representação de injustiça nessa realidade. Estas mulheres trabalham, estudam, cuidam do lar e dos filhos, e não se conscientizam dessa dupla jornada. Possivelmente essa legitimação da responsabilidade, ou seja, da extra jornada, dá-se de maneira subtil, como foi observado por Hirata e Kergoat (2007) que apontam o fato de que o mais espantoso é a maneira como as mulheres, mesmo plenamente conscientes da desigualdade da divisão do trabalho doméstico, continuam a se incumbir do essencial desse trabalho doméstico, inclusive entre as militantes feministas.

Ao contrário do que se poderiam esperar, os estudos têm demonstrado que, mesmo com a crescente participação da mulher no mercado laboral, o mesmo crescimento não encontra seu equivalente quanto à colaboração do cônjuge nas tarefas domésticas. E nesse sentido, uma análise histórica e sociológica, mesmo que superficial, "[...] é suficiente para colocar em evidência o caráter essencial das atividades realizadas pelas mulheres na manutenção e desenvolvimento dos 


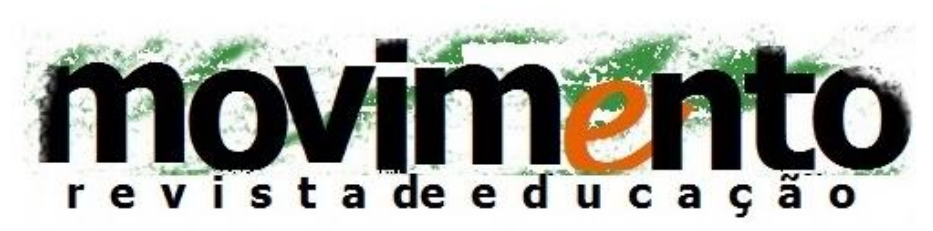

faculdade de educação - programa de pós-graduação em educação

universidade federal fluminense

issn 2359-3296

ano 3 número 5 - 2016

núcleos familiares e das comunidades respectivas" (BALLARÍN et al., 2005, p. 14).

A entrada generalizada das mulheres no mercado de trabalho, considerada como dado estrutural das sociedades contemporâneas teve consequências variadas, diretas e indiretas na vida conjugal e familiar. Consequências diretas porque tal tendência rompe, embora apenas parcialmente, com um modelo ideal de relação entre trabalho e família, dominante durante grande parte do século XX e até meados dos anos 1960. Estando ou não no mercado de trabalho remunerado, todas as mulheres são donas-de-casa e realizam tarefas que, mesmo sendo indispensáveis para a sobrevivência e o bem-estar de todos os indivíduos, são desvalorizadas e desconsideradas nas estatísticas, que as classificam como "[...] inativas, cuidam de afazeres domésticos" (BRUSCHINNI e LOMBARDI, 2006, p. 3). Se estas atividades domésticas fossem consideradas como profissão, com dedicação integral, o nível de participação entre homem e mulher como economicamente ativos, estariam praticamente igualados.

Sem dúvida que o século $X X$ e o começo do $X X I$ testemunharam o avanço de mudanças profundas na vida dos brasileiros e principalmente das brasileiras. $O$ aumento de escolaridade feminina, a massiva entrada no mercado de trabalho, e o aumento dos domicílios chefiados por mulheres são algumas das alterações mais significativas observadas na condição feminina nas últimas décadas. Diante desse quadro, um dos maiores pontos de tensão na vida dessas mulheres é a articulação entre o trabalho remunerado (produtivo) e o trabalho doméstico (reprodutivo).

O que persiste, como vemos é a distância entre a igualdade legal formal e política e a prática de todos os dias. Os direitos e os princípios mantiveram-se teóricos, 


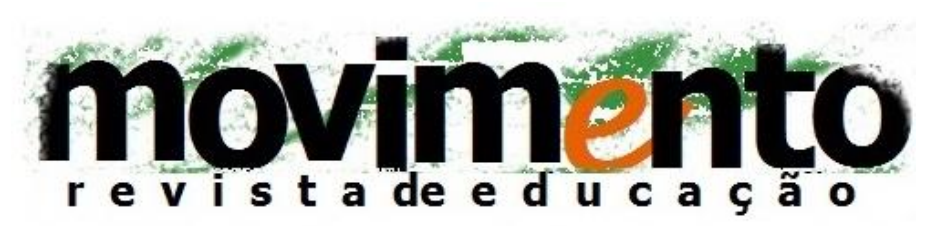

faculdade de educação - programa de pós-graduação em educação

universidade federal fluminense issn 2359-3296

ano 3 número 5 - 2016

especialmente em termos socioeconômicos e no que diz respeito às vidas privadas das mulheres. Ao confrontarmos o espaço conquistado pelas mulheres e as necessidades ainda existentes para atingirmos uma sociedade justa, concluímos que no Brasil devemos intensificar o debate por políticas públicas e por mudanças culturais que promovam a igualdade de tratamento entre homens e mulheres.

\section{Referências Bibliográficas}

AMÂNCIO, L. Masculino e Feminino: A Construção Social da Diferença. Porto: Afrontamento, 1994.

AMÂNCIO, L. \& OLIVEIRA, J.M. Liberdades condicionais: o conceito de papel sexual revisitado. Sociologia, Problemas e Práticas, n.ำ40, 2002, (pp. 45-61). Disponível em < http://www.scielo.mec.pt/pdf/spp/n40/n40a03.pdf $\geq$ Acesso em 02 de setembro de 2015.

BALLARÍN, P.; BIRRIEL, M.M., MARTINEZ, C. \& ORTIZ, T. As mulheres e a história da Europa. Lisboa: Rede de Estudos das Mulheres,2005.

BOURDIEU, P. Introdução a uma sociologia Reflexiva. In: O poder Simbólico. 5쯜. Rio de Janeiro: Bertand, 2002, pp.17-58.

BRUSCHINNI, M.C.A. \& LOMBARDI, M. R. Mulheres, trabalho e família. Rio de Janeiro: Fundação Carlos Chagas, 2006. Disponível em 


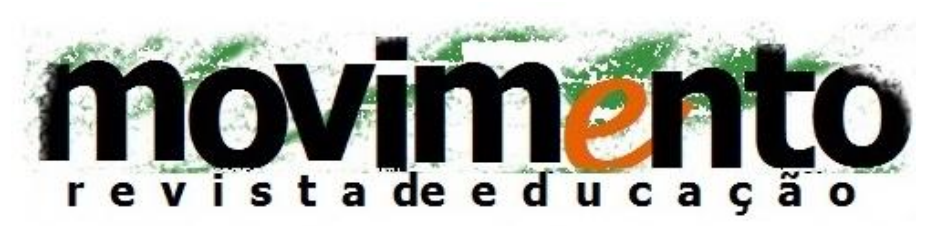

faculdade de educação - programa de pós-graduação em educação

universidade federal fluminense issn 2359-3296

ano 3 número 5 - 2016

$<$ http://www.fcc.org.br/conteudosespeciais/difusaoideias/pdf/materia_mulheres_ trabalho_e_familia.pdf>Acesso em 20 de setembro de 2015.

CHIZZOTTI, A. A pesquisa em ciências humanas e sociais. $4^{a} e d$. São Paulo: Cortez, 2000.

DOMINGOS, L. Concepções e experiências de conciliação entre a vida profissional, familiar e pessoal: a perspectiva das pessoas que trabalham numa autarquia. Dissertação de Mestrado em Serviço Social. Universidade Católica Portuguesa - Centro Regional das Beiras - Polo de Viseu, Departamento de Economia, Gestão e Ciências Sociais - Mestrado em Serviço Social, 2012.

GOLDANI, A. M. Família, Género e Políticas: famílias Brasileiras nos anos 90 e seus desafios como fator de proteção. Revista Brasileira de Estudos de População, no19(1), 2002, pp.29-48.

HARAWAY, D. "Gênero" para um dicionário marxista: a política sexual de uma palavra. Cadernos Pagu (22) 2004: pp.201-246. Disponível em $<$ http://www.scielo.br/pdf/cpa/n22/n22a09.pdf $\geq$ Acesso em 03 de outubro de 2016.

HIRATA, H. \& KERGOAT, D. Novas configurações da divisão sexual do trabalho. Tradução: Fátima Murad. Cadernos de Pesquisa, v. 37, n. 132, set./dez, 2007.

LOURO, G. L. Gênero, sexualidade e educação: uma perspectiva pósestruturalista. 6ed. Petrópolis, RJ: Vozes, 2007. 


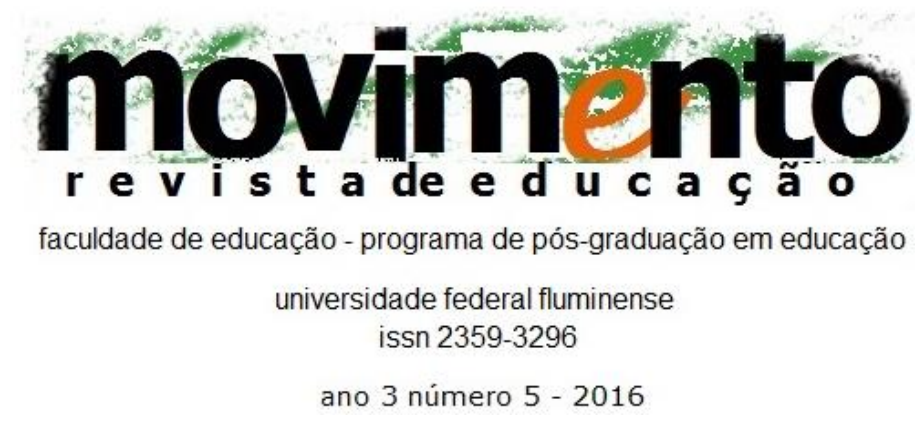

NÚNCIO, M. J. S. Mulheres em dupla jornada - A conciliação entre trabalho e família. Lisboa: Editora Instituto Superior de Ciências Sociais e Políticas, 2008.

PARSONS, T. Family structure and the socialization of the child, in PARSONS, T; BALES, F. (Orgs.), Family, Socialization and Interaction Process. Londres: Routledge, 1956.

TORRES, A.; Silva, F. V.; MONTEIRO, T. L. \& CABRITA, M. Homens e mulheres entre família e trabalho. 2aㅡ ed. Lisboa: DGEEP.CID, 2005. 